\title{
Hydrometeorological Reconstructions for Northeastern Mongolia Derived from Tree Rings: 1651-1995*
}

\author{
Neil Pederson, Gordon C. Jacoby, Rosanne D. D’Arrigo, Edward R. Cook, And \\ BRENDAN M. BUCKLEY \\ Tree-Ring Laboratory, Lamont-Doherty Earth Observatory, Palisades, New York \\ Chulteminn Dugarjav \\ Institute of Biotechnology, Ulaanbaatar, Mongolia \\ R. MIJIDDORJ \\ Hydrometeorological Research Institute, Ulaanbaatar, Mongolia
}

(Manuscript received 20 December 1999, in final form 2 June 2000)

\begin{abstract}
Reconstructions of annual (prior August-current July) precipitation and streamflow, $345 \mathrm{yr}$ in length (16511995), are presented for northeastern Mongolia based on tree-ring width data. These precipitation and streamflow reconstructions account for $54 \%$ and $48 \%$ of the respective variance in instrumental data over the past 50 years. Variations in instrumental precipitation and streamflow are within the range of those reconstructed over the length of tree-ring records. However, there appear to be more frequent extended wet periods during the twentieth century. Multitaper spectral analysis revealed statistically significant peaks at 10.8 and $12.8 \mathrm{yr}$ for the precipitation reconstruction, and at 12.8 and $20.3-23.8$ yr for the streamflow reconstruction. Similarly, singular spectrum analysis identified spectral modes of variation at 12 and $21 \mathrm{yr}$ for both series. These spectra resemble those found for tree-ring-based precipitation reconstructions in central China as well as the western United States, and may reflect solar influences on the climate of Mongolia.
\end{abstract}

\section{Introduction}

Fluctuations in precipitation profoundly impact the agrarian economy and nomadic segment of Mongolian culture. In 1999 a severe summer drought followed by heavy winter snowfall triggered starvation and death of an estimated two million of the nation's livestock. Mongolia is characterized by an extremely continental climate, predominantly influenced by the Siberian high pressure cell, also called the Mongolian or Asiatic high, which is often centered over northern Mongolia from winter through late spring (Zhang and Lin 1992; An and Thompson 1998; Samel et al. 1999). Mongolia is situated where the midwesterly jet converges with monsoonal airflow from the southwest (Yatagai and Yasunari 1995). Other circulation systems that influence central

* Lamont-Doherty Earth Observatory Contribution Number 6094.

Corresponding author address: Neil Pederson, Tree-Ring Laboratory, Lamont-Doherty Earth Observatory, Palisades, NY 10964. E-mail: adk@1deo.columbia.edu
Asia precipitation are the east Asia monsoon (Xue 1996; An and Thompson 1998; Samel et al. 1999), Indian summer monsoon (Yatagai and Yasunari 1995; Xue 1996), North Pacific high (Yatagai and Yasunari 1995), and El Niño-Southern Oscillation (Yatagai and Yasunari 1994; Mijiddorj and Jigmeddorj 1993; Yatagai and Yasunari 1995; Meiyu et al. 1995). Mongolia lies near the limit of these effects and apparently no single system consistently dominates the climate. In summer, local radiation balances and convective storms influence Mongolian climate (Zhang and Lin 1992).

A study of instrumental precipitation data for eastern Mongolia indicates that summer rainfall has increased since the 1940s (Dagvadorj and Mijiddorj 1996), while a concomitant decrease since the 1950s has been observed in southern Mongolia (Yatagai and Yasunari 1995). A recent study of dry and wet intervals around the globe from 1900 to 1995 found a slight increase in extreme events and areal coverage of severe drought or moisture surplus in some areas of Asia since the late 1970s (Dai and Trenberth 1998). General circulation model experiments suggest that drought variations at mid- to high northern latitudes (such as Mongolia) may 
become more frequent or extreme under conditions of elevated temperature (e.g., Kattenburg et al. 1996). Such analyses illustrate the need for longer records in order to place these recent or projected changes into a longterm perspective for Mongolia and elsewhere in northern Asia.

Tree rings have been employed successfully to reconstruct precipitation, streamflow (which integrates precipitation over an entire drainage basin), and other meteorological variables for many areas of the earth (e.g., Schulman 1945; Stockton and Jacoby 1976; Cook and Jacoby 1983; Cleaveland and Stahle 1989; D'Arrigo and Jacoby 1991; Boninsegna 1992; Grissino-Mayer 1996; Cook et al. 1997). Yet few such reconstructions exist for northern and central Asia, and these are mainly in China (Wu 1992; Hughes et al. 1994) with almost no such records available for Mongolia. A recent study presented a temperature-sensitive tree-ring record of $\mathrm{Si}$ berian pine from alpine treeline $(2290 \mathrm{~m})$ in the Tarvagatay Mountains of north-central Mongolia (Jacoby et al. 1996). In this paper, we present some of the first hydrometeorological reconstructions for this region, based on drought-sensitive trees from lower-forest border sites in northeastern Mongolia. These reconstructions provide a long-term perspective for drought variations recorded in the instrumental data over the past 50 years. They also yield longer time series with which to begin to consider the relative roles of natural climate forcings versus possible anthropogenic influences on precipitation over the past several centuries.

\section{Data and methods}

\section{a. Tree-ring records}

Standard dendrochronological techniques were applied in this analysis (Stokes and Smiley 1968; Fritts 1976; Holmes 1983; Cook and Kairiukstis 1990). Trees at or near the forest-grassland ecotone (i.e., lower forest border) are often moisture stressed and record varying precipitation in their annual ring widths (Fritts 1976). Since our interest for this study was the reconstruction of hydrometeorological variables, we selected trees from lower forest border sites where there was little or no apparent evidence of human or other disturbance. These sites were characterized by having widely spaced trees and sparse ground vegetation, both indicators of a drought-stress environment.

Two such sites were found in northeastern Mongolia. One of these was a Scots pine (Pinus sylvestris L.) lower forest border site at Urgun Nars (UN), at $48^{\circ} 34.6^{\prime} \mathrm{N}$, $110^{\circ} 32.7^{\prime} \mathrm{E}$, elevation $1070 \mathrm{~m}$ (Fig. 1). The other location sampled was for Siberian larch (Larix sibirica Ledebour) from a disjunct stand within a semiarid grassland ecosystem at Zuun Mod (ZM) at $47^{\circ} 47.2^{\prime} \mathrm{N}$, $107^{\circ} 30.0^{\prime} \mathrm{E}$, elevation $1415 \mathrm{~m}$ (Fig. 1). In the Mongolian region, these two species are often the dominant trees in the dry lower-elevation transitional vegetation zones (Price and Simpson 1913; Wang 1961).

The raw ring-width measurements for these two sites were standardized using the ARSTAN method that creates a mean-value series of ring-width indexes for all samples available for each year (Cook 1985). The standardization process involved detrending of individual tree-ring series using either negative exponential, linear regression of negative slope to zero slope, or 400-yr smoothing spline curve fits. With the option we selected, the ARSTAN program makes data-based decisions on whether the negative exponential detrending or linear regression is appropriate. We also selected a 400-yr spline in a few cases when there appeared to be anomalous low-frequency trends different from the common trends of the rest of the trees. Our intent with this methodology is to remove biological growth trends while preserving variations of all frequencies that may be related to climate (Cook and Kairiustis 1990). The final UN chronology extends from 1651 to 1996 , and is composed of data from 16 trees and 33 cores (with 4 series extending back to 1661 and 8 to 1668), and has a mean segment length of $189 \mathrm{yr}$. The final ZM chronology dates from 1582 to 1996 , consists of data from 13 trees and 30 individual series (with 3 cores dating back to 1583 and 10 back to 1593), and has a mean segment length of $332 \mathrm{yr}$.

The rbar (Briffa 1995) and expressed population signal (EPS; Wigley et al. 1984) statistics are two parameters for evaluating the quality of tree-ring chronologies (Cook and Kairiukstis 1990). The rbar, the mean correlation coefficient between all tree-ring series used in a chronology, was 0.652 for UN and 0.690 for ZM. The EPS, a function of both rbar and sample size, exceeds 0.965 for every 30 -yr segment over the lengths of record for both chronologies, well above the 0.85 threshold value that is considered acceptable by some researchers (Wigley et al. 1984; Cook and Kairiukstis 1990). Based on these evaluations we consider these chronologies to be valid for use in dendroclimatic reconstruction as outlined below. Correlation functions between the tree chronologies and monthly instrumental data were calculated to identify the season for reconstruction (Fig. 2).

We used the multitaper method (MTM) to evaluate the spectral properties of the reconstructions. MTM has several advantages over single-taper methods, including reduced bias from data leakage, production of direct spectral estimates with multiple degrees of freedom, and a better trade-off between spectral resolution and statistical variance than single-taper methods (Percival and Walden 1993; Mann and Lees 1996). Significance tests were calculated following Mann and Lees (1996). The calculation of the null hypothesis was performed by the robust noise background estimation procedure. This method uses median smoothing of the spectrum to estimate background noise insensitive to the peaks (Mann and Lees 1996). Blackman-Tukey (BT) cross-spectral 


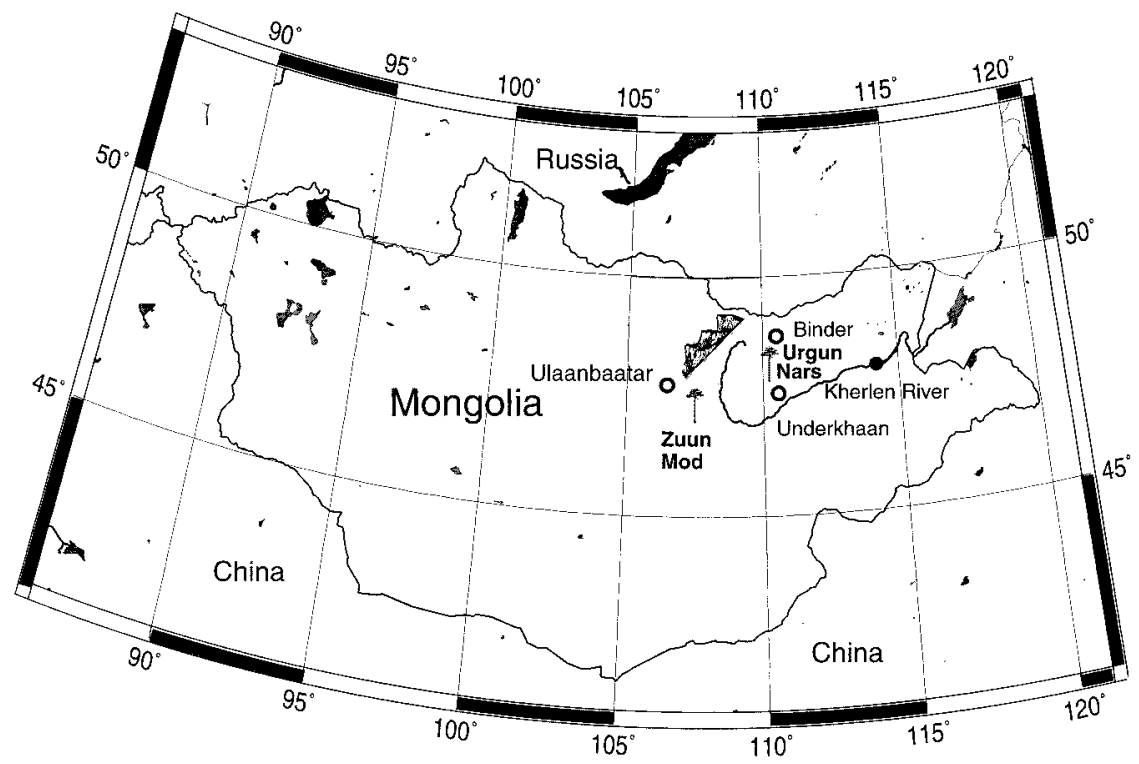

FIG. 1. Location of sampling sites and meteorological stations in Mongolia. A tree symbol represents the UN and ZM sites. Tree site names are bold. Hollow circles $\left(\mathrm{O}_{\text {) }}\right.$ are meteorological stations. The solid circle $(-)$ represents the streamflow gauge location. The shaded area approximates the watershed modeled. Only the mountain range of the watershed is pictured.

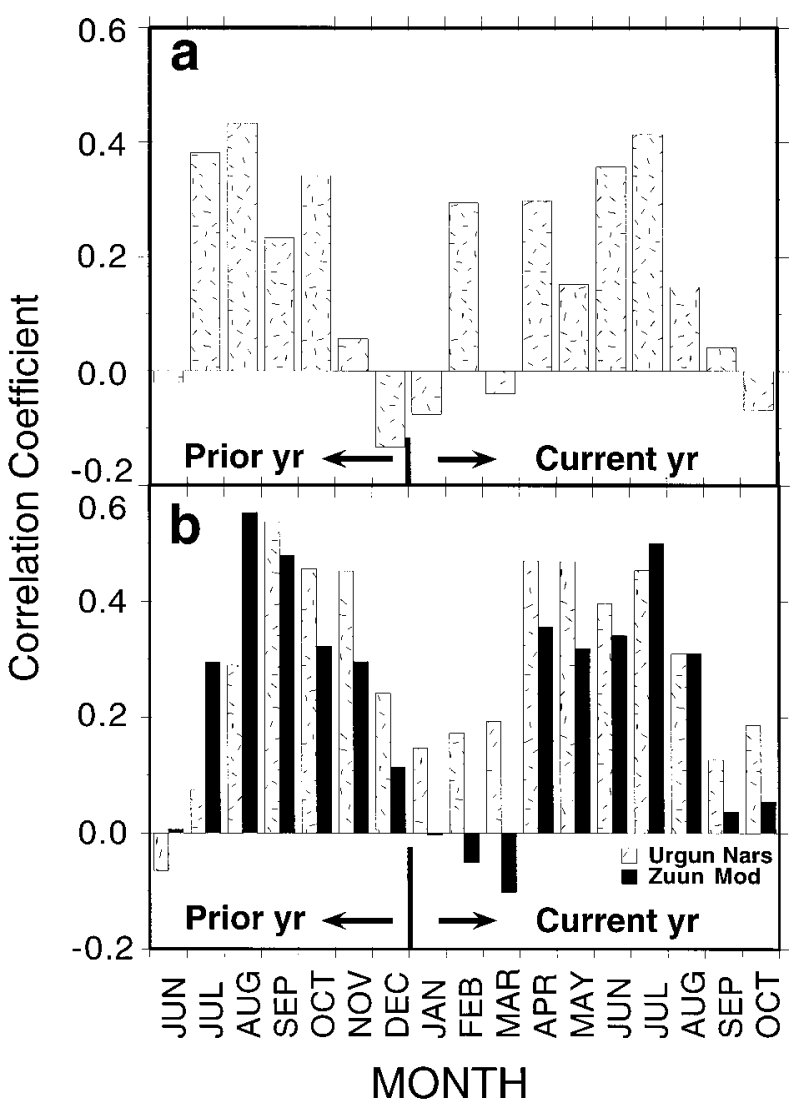

FIG. 2. Monthly correlation coefficients of (a) UN tree-ring chronology and instrumental precipitation data and (b) UN (stipled bars) and ZM (solid bars) tree-ring chronologies with instrumental Kherlen River streamflow data. analysis (Jenkins and Watts 1968) was used to explore spectral coherency between the reconstructions and instrumental hydrometeorological records. Singular spectrum analysis (SSA) was also employed to further explore the spectral properties of the reconstructions. SSA is a data-adaptive method for extracting oscillatory signals from noise in time series (Vautard 1995). Maximum entropy spectral analysis (MEM) was used to explore the spectral properties of the bidecadal waveforms extracted by SSA (Marple 1987). The autoregressive component used in MEM analysis was the prediction error filter length, which is $20 \%$ of the series length. Using multiple spectral analysis methods helped to evaluate the stability of the spectral properties.

\section{b. Hydrometeorological records}

\section{1) Precipitation}

Instrumental hydrometeorological records were provided by the Hydrometeorological Research Institute in Ulaanbaatar, Mongolia. Limiting factors of climatic reconstruction in Mongolia are short instrumental records and a low-density meteorological station network. The records used for these reconstructions are the best climatic time series available for the region of this study. For dendroclimatic modeling, hydrometeorological data must have sufficient length for regression analysis.

Precipitation records used were the only three long and continuous meteorological stations close to the treering sites: Binder, Ulaanbaatar, and Underkhaan (Fig. 1). All station records were significantly correlated with each other ( $r$ ranging $0.36-0.56 ; p$ value $<0.05$ ) over 
the dendroclimatic year modeled indicating spatial coherency. These series were averaged over the common interval from 1941 to 1995 . Averaging precipitation records from different stations can decrease small-scale noise and improve statistical relationships between trees and meteorological data (Blasing et al. 1981). Mean annual precipitation for this three-station average is $278.6 \mathrm{~mm}$ (standard deviation (SD; $56.3 \mathrm{~mm}$ ), with summer (June-August) rainfall accounting for nearly $74 \%$ of the total.

\section{2) Streamflow}

Monthly streamflow data for the Kherlen River at the Choibalsan hydrologic station (Fig. 1) were available from 1947 to 1994 . There are no significant reservoirs or diversions of the Kherlen River above the gauge point. Mean annual streamflow is $253.14 \mathrm{~m}^{3} \mathrm{~s}^{-1}$ (SD $116.85)$. Data from two of the precipitation stations are located within this drainage basin; hence, the meteorological series are not independent from the streamflow data.

\section{Results}

\section{Hydrometeorological reconstructions}

\section{1) PRECIPITATION}

The best precipitation model, obtained using linear regression techniques (Cook and Kairiukstis 1990), was derived using the UN tree-ring record alone; addition of the ZM chronology did not improve the results. The ZM correlated more highly with the streamflow data (see below). The best precipitation relationship was found when the UN series was correlated with the threestation precipitation average over the months from previous August to July of the current year of growth for 1942-95 ( $r=0.742$; Fig. 2a). Based on our own sampling in Mongolia in August, we observe that radial growth is nearly complete by the beginning of August. Current August precipitation has a much lower correlation with ring width than prior August (Fig. 2a). Trees can respond to favorable soil moisture and photosynthetic conditions prior to the growing season, with these conditions integrated into the current year's growth ring (Fritts 1976; Kramer and Kozlowski 1979). Tree growth had a weak negative correlation to temperature during the growing season. We interpreted this as being due to the relationship of high temperature with drier conditions. Intercorrelation of the three-station precipitation and temperature instrumental data verified that temperature and precipitation are negatively correlated in northeastern Mongolia. The resulting Urgun Nars precipitation reconstruction (UNP) accounts for $54.2 \%$ of the variance ( $a r^{2}$, adjusted for degrees of freedom) over the 1942-95 calibration period (Fig. 3a, Table 1). The final UNP reconstruction from 1651 to 1995 is presented in Fig. 4a.

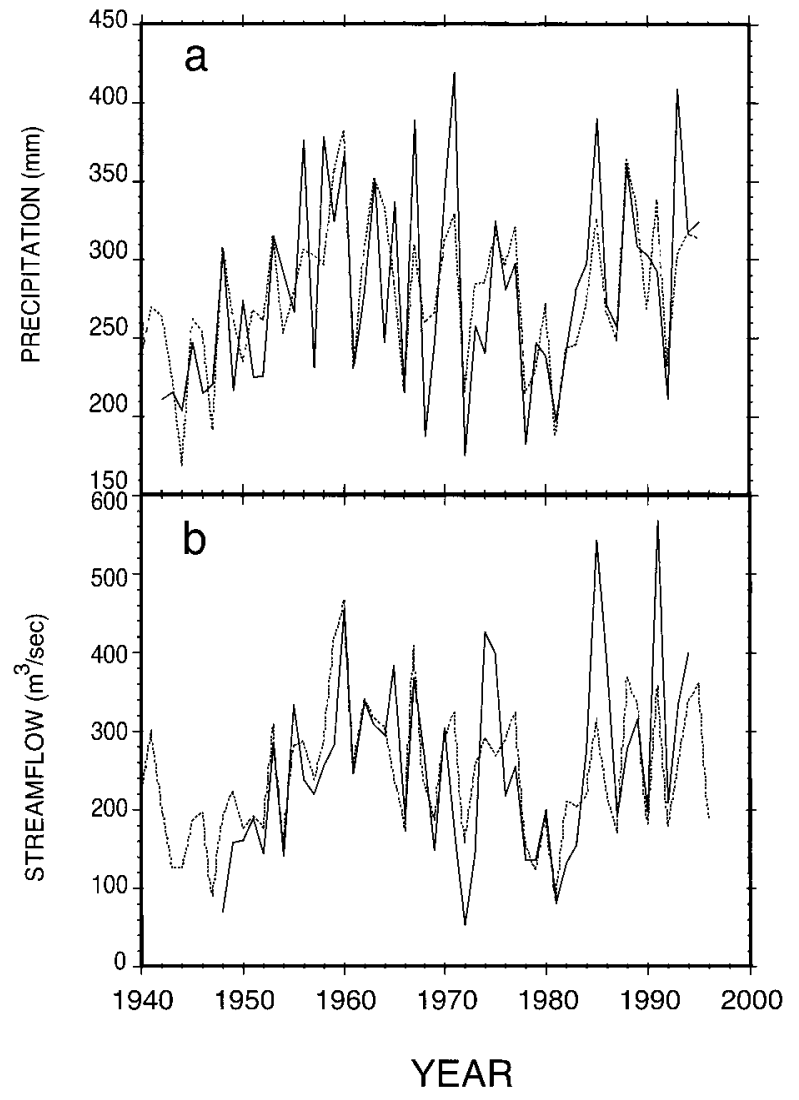

FIG. 3. Recorded (solid line) and reconstructed (dashed line) (a) UN precipitation from 1942 to 1995 and (b) Kherlen River streamflow from 1948 to 1994.

\section{2) Streamflow}

Using principal components analysis, UN and ZM series were used to predict streamflow at the Kherlen River. Combining UN and ZM results in a loss of data from 1582 to 1650 (due to the 1651 beginning of the UN chronology). The UN and ZM chronologies responded similarly to the same season of climate (Fig. $2 b)$. There were different growth responses during the winter. Kherlen River streamflow is at an annual low from January to March [mean seasonal flow $14.1 \mathrm{~m}^{3}$ per second (SD 29.0)] representing 6\% of the mean annual flow. Measurements at such low flow are less reliable than higher flows (Linsley et al. 1949). Thus, the response differences at low flow and low correlation are likely unimportant. From 1948 to 1994, the combined UN and ZM predictors correlated at $r=0.703$ for the same August-July interval used for precipitation. The Kherlen River streamflow reconstruction (KRS) model accounted for $48.2 \%$ of the variance $\left(a r^{2}\right)$ over the period of calibration (Fig. 3b, Table 1). The final KRS reconstruction is shown in Fig. $4 b$.

\section{3) Model VERIFICATION}

Split-sampling calibration and verification tests were used to evaluate the quality and stability of both recon- 
TABLE 1. Reconstruction statistics for UN precipitation and Kherlen River streamflow dendroclimatic year (previous Aug through current Jul). Common periods in meteorological data tested are 1942-95 for UN and 1948-94 for Kherlen River. The adjusted $r^{2}=$ variance explained adjusted for loss of degrees of freedom; $(*)=$ level of probability $<0.05 ;(* *)=$ level of probability $<0.01 ;(* @)=1$ level of probability $<0.002 ;(@)=1$ level of probability $<0.001$.

\begin{tabular}{|c|c|c|c|c|c|}
\hline & \multicolumn{5}{|c|}{ Urgun Nars } \\
\hline & $\begin{array}{c}\text { 1942-68 } \\
\text { Calibration }\end{array}$ & $\begin{array}{c}\text { 1969-95 } \\
\text { Verification }\end{array}$ & $\begin{array}{c}\text { 1969-95 } \\
\text { Calibration }\end{array}$ & $\begin{array}{c}\text { 1942-68 } \\
\text { Verification }\end{array}$ & $\begin{array}{c}\text { 1942-95 } \\
\text { Final } \\
\text { calibration }\end{array}$ \\
\hline Variance explained & 0.475 & - & 0.646 & - & 0.550 \\
\hline Adjusted $r^{2}$ & 0.454 & - & 0.632 & - & 0.542 \\
\hline Pearson correlation coefficient & 0.689 & 0.804 & 0.804 & 0.689 & 0.742 \\
\hline Reduction of error & 0.475 & 0.600 & 0.646 & 0.432 & - \\
\hline Coefficient of efficiency & 0.475 & 0.581 & 0.646 & 0.403 & - \\
\hline Product means test & 0.178(*@) & 0.194(@) & 0.295(@) & $0.229(* *)$ & - \\
\hline \multirow[t]{3}{*}{ Sign test } & $22^{+} / 5^{-}(* @)$ & 24+/3-(@) & $22^{+} / 5^{-}(* @)$ & $22^{+} / 5^{-}(* @)$ & - \\
\hline & \multicolumn{5}{|c|}{ Kherlen River } \\
\hline & $1948-70$ & $1971-94$ & $1971-94$ & $1948-70$ & $1948-94$ \\
\hline Variance explained & 0.649 & - & 0.450 & - & 0.494 \\
\hline Adjusted $r^{2}$ & 0.632 & - & 0.425 & - & 0.482 \\
\hline Pearson correlation coefficient & 0.805 & 0.681 & 0.670 & 0.825 & 0.703 \\
\hline Reduction of error & 0.649 & 0.395 & 0.450 & 0.442 & - \\
\hline Coefficient of efficiency & 0.649 & 0.393 & 0.450 & 0.438 & - \\
\hline Product means test & $5090.6(* *)$ & 8202.2(@) & $9090.9(* *)$ & $7832.0(* *)$ & - \\
\hline Sign test & 20+13-(@) & $17^{+} / 7^{-}(*)$ & $18^{+} / 6^{-(*)}$ & 21+/2-(@) & - \\
\hline
\end{tabular}

struction models (Fritts 1976; Cook and Kairiukstis 1990). Residual analysis indicated a statistical autocorrelation in the streamflow reconstruction over the 194894 period (calculated Durbin-Watson statistic $(\mathrm{D}-\mathrm{W})=$ 1.26 for $n=47 ; 5 \%$ significance value $=1.49)$. A calculated value less than the significance value indicates a significant relationship (Draper and Smith 1981). This relationship was not significant for the 1948-70 period, but was significant for the 1971-94 period (calculated $\mathrm{D}-\mathrm{W}=1.08$ for $n=24$; significance $\mathrm{D}-\mathrm{W}=$ 1.27). Inspection of the instrumental streamflow data indicated that three unusual years $(1985,1986,1991)$

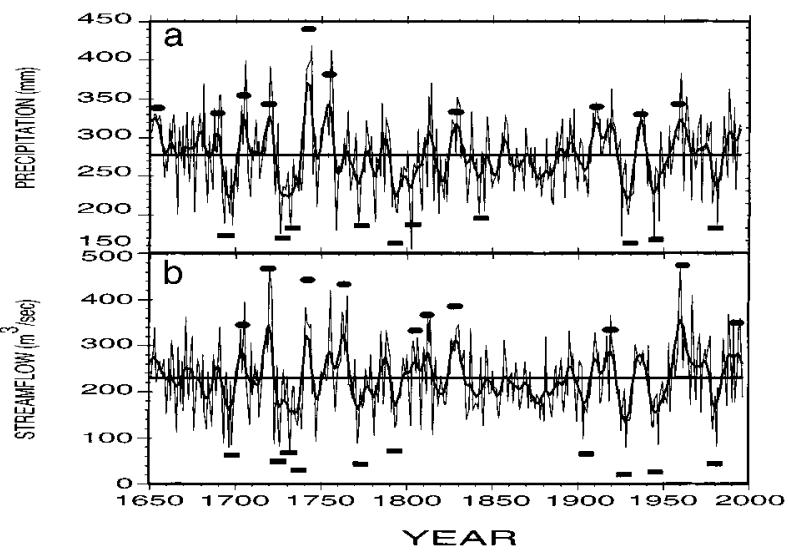

FIG. 4. Reconstruction of (a) UN precipitation and (b) Kherlen River streamflow. The thin line is reconstructed data. The thick, curvilinear line is the $10-\mathrm{yr}$ cubic smoothing spline. The solid, flat line is the reconstruction mean. Filled ovals signify extreme wet intervals. Filled rectangles signify extreme dry intervals. Extreme intervals were averaged over 5-yr periods and ranked to identify the top 10 wet and dry 5-yr intervals. account for much of the trend. Removing these data points greatly reduced the trend in the data. A prewhitening experiment gave the following results: 1) the trend in the instrumental data was not significant and 2) prewhitening of the tree-ring data did not produce a significantly different relationship between tree growth and streamflow. Seven verification tests were significant at the 0.001 level or better. Only sign tests for the 197194 period were not significant at the 0.01 level $(0.033$ and 0.012 , respectively; see below). The consensus of the verification tests indicate a highly significant and valid model. Therefore, we decided to use the original reconstruction.

Verification tests indicate that both reconstructions captured the low- and high-frequency variations of the recorded data well (Figs. 2a,b) despite the fact that trees tend to underestimate extreme seasons or years (Fritts 1976; Young 1994). For example, the reduction of error and coefficient of efficiency statistics, both considered to be rigorous tests of model validation, were positive, providing evidence that the reconstructions exhibit positive skill in estimating the climate information (Fritts 1976; Cook et al. 1994; Table 1). Product-means tests, a measure of the sign and magnitude of departure from the calibration mean, were significant at or above the 0.01 level. The sign test results, an indication of how well the tree-ring estimates track the direction of change in climate from year to year, were significant at or above the 0.05 level for both series.

\section{4) Evaluation of HYDROMETEOROLOGICAL DATA}

The three-station precipitation data were used to estimate the streamflow data for intercomparison with the 
TABLE 2. Top 10 5-yr dry and wet periods for UN and Kherlen River reconstructions.

\begin{tabular}{|c|c|c|c|c|c|}
\hline \multirow[b]{3}{*}{ Rank } & \multicolumn{2}{|c|}{ Urgun Nars precipitation } & \multicolumn{3}{|c|}{ Kherlen River streamflow } \\
\hline & \multicolumn{5}{|c|}{ Time interval (average) } \\
\hline & \multirow{2}{*}{$\begin{array}{c}\text { Dry } \\
1928-32(21.8)\end{array}$} & \multirow{2}{*}{$\begin{array}{c}\text { Wet } \\
1740-44(38.9)\end{array}$} & \multicolumn{2}{|c|}{ Dry } & \multirow{2}{*}{$\begin{array}{c}\text { Wet } \\
1959-63(357.8)\end{array}$} \\
\hline 1 & & & $1925-29$ & (139.6) & \\
\hline 2 & $1791-95(21.8)$ & $1752-56(35.3)$ & $1943-47$ & (142.5) & $1717-21(354.6)$ \\
\hline 3 & $1943-47(22.1)$ & $1702-06$ (33.6) & $1725-29$ & (144.6) & $1740-44(342.8)$ \\
\hline 4 & $1725-29(22.2)$ & $1717-21(32.9)$ & $1771-75$ & (150.7) & $1761-65(338.2)$ \\
\hline 5 & $1692-96(22.4)$ & $1956-60(32.9)$ & $1978-82$ & (151.0) & $1826-30(315.6)$ \\
\hline 6 & $1978-82(23.0)$ & $1908-12(32.7)$ & $1723-27$ & (153.3) & $1810-14(306.1)$ \\
\hline 7 & $1731-35(23.0)$ & $1652-56(32.6)^{*}$ & $1696-1700$ & (160.4) & $1991-95(297.9)$ \\
\hline 8 & $1771-75(23.2)$ & $1826-30(32.3)$ & 1903-07 & (161.4) & $1702-06(296.0)$ \\
\hline 9 & $1801-05(23.3)$ & $1687-91(32.2)$ & $1729-33$ & (162.6) & $1917-21(290.3)$ \\
\hline 10 & $1841-45(23.8)$ & $1934-38(32.1)$ & 1791-95 & (164.4) & 1803-07 (289.8) \\
\hline
\end{tabular}

* This interval should be interpreted with caution since it is represented by only one series.

tree-ring estimates. Both trees and streamflow integrate evapotranspiration effects in addition to precipitation input. Analysis of the precipitation-streamflow data showed that the preceding month's precipitation is the best estimator for current month streamflow. Therefore, a 12-month total precipitation for July through June was used to estimate August through July streamflow (the hydrologic year estimated by the tree-ring data). Results showed that the precipitation accounted for $38.5 \%$ of the variance $\left(a r^{2}\right)$ in streamflow, notably less than the tree-ring estimates. Using only the two rain gauges within the Kherlen River basin produced even poorer results. Based on the area of a standard rain gauge and the total area of root extension for trees sampled at each site, tree-ring sampling covers orders of magnitude more surface area than the three rain gauges. Stahle and Cleaveland (1992) found that a single meteorological station explained only 6\%-13\% more precipitation variation than tree-ring chronologies in the southeastern United States. Thus, tree-ring records can make good estimates of regional moisture conditions.

\section{5) HYDROMETEOROLOGICAL VARIABILITY}

To evaluate precipitation and streamflow variability over the lengths of the reconstructions, we calculated the 10 most extreme nonoverlapping wet and dry 5-yr intervals for both reconstructions (Table 2). Compared to the rest of the reconstruction, unusual clustering of extreme wet or dry intervals was not obvious in the modern period (Figs. 4a,b). Further, the standard deviation of UNP was slightly lower from 1942 to 1995 (46.6) than from 1651 to 1850 (50.2), the interval prior to a period of reduced amplitude from 1847 to 1907 (see below). However, for KRS, the std dev was higher for 1948-94 (821.0) relative to 1651-1850 (SD 756.5). There is some indication of extended wetter periods in the twentieth century, especially the 1900 s to 1920 and 1950s-1960s (Figs. 4a,b). Although it is possible that the variable periods in the early parts of these records may be related to a decreasing sample size, the strong EPS statistics suggest this is probably not the case.

One feature of interest in both reconstructions is a period of low variability from the late 1840 s to early 1900s. This feature is reflected in the std dev which is only 30.0 for the precipitation reconstruction from 1847 to 1907 , compared to a value of 49.1 for the reconstruction excluding that time interval. Similarly, the std dev for the streamflow reconstruction is 483.6 for 18471907 , and 769.8 for the rest of the reconstruction.

\section{6) SPeCtral ANALYSis}

Using MTM methods, the instrumental precipitation record and UNP reconstruction from 1942 to 1995 had significant (95\% level) spectral coherency at 2.0, 2.8, $4.1,6.2,8.3$, and $12.5 \mathrm{yr}$ with broad peaks centered at 25 and 50 yr. The recorded streamflow data and the KRS reconstruction from 1947 to 1994 had significant (95\% level) spectral coherency at 2.5-2.9, 3.5, 6.2, and $16.7 \mathrm{yr}$. Due to the shortness of the instrumental hydrometeorological data, the lower-frequency results should be interpreted with caution.

Using MTM methods over the full length of the precipitation reconstruction, UNP had significant peaks at $10.8(90 \%)$ and $12.8 \mathrm{yr}(95 \%$; Fig. 5a). Lower-frequency peaks (not significant) were found at 16.7, 19.3, and 23.3 yr. Significant (95\% level and higher) high-frequency peaks for UNP were found at 2.1, 2.7, 3.0, 3.3, and 3.5. For the full KRS reconstruction, significant peaks were identified at 12.8 and 20.3-23.8 yr (95\%; Fig. 5b). Significant (95\% level and higher) high-frequency peaks for KRS were found at 2.2-2.3, 2.7, 3.1, and 3.4-3.6. We concentrated our analyses on the lowfrequency peaks to evaluate bidecadal drought.

The dominant waveforms extracted with SSA (using a 60-yr lag) for UNP were at 12.3 (eigenvector pair 2 and 3) and $21.3 \mathrm{yr}$ (pair 5 and 6). These waveforms accounted for $9.75 \%$ and $8.06 \%$ of the total variation, respectively. Using a 100-yr lag for KRS, waveforms 


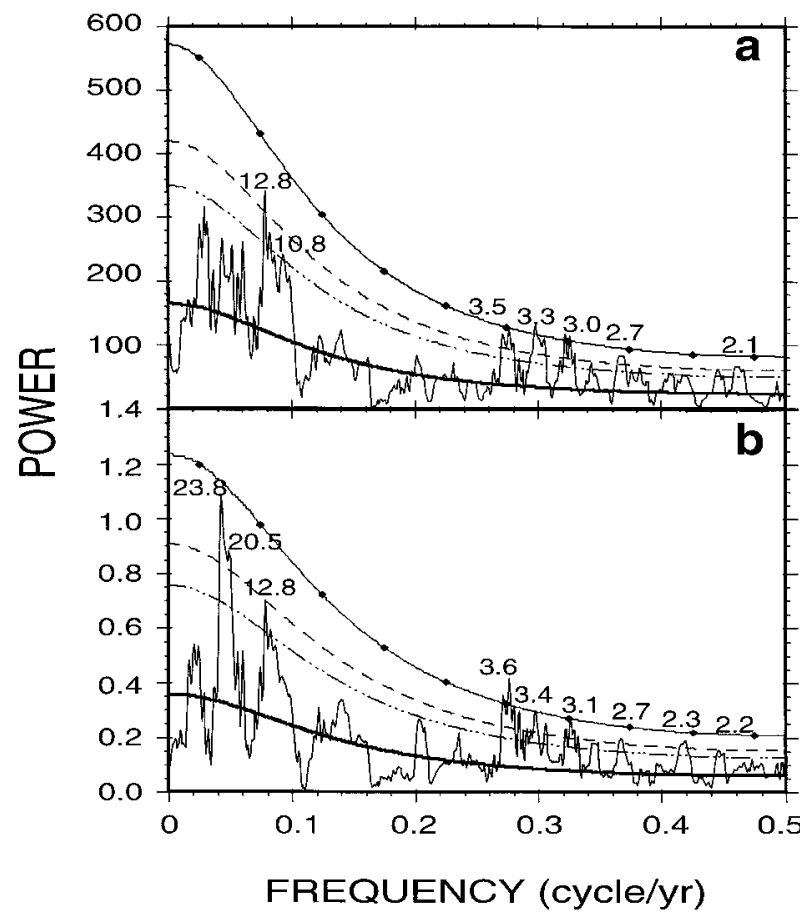

FIG. 5. MTM spectral densities of (a) UN precipitation reconstruction and (b) Kherlen River streamflow reconstruction. The thick solid line $=$ the null hypothesis. Dot and dashed line $=$ the $90 \%$ confidence level; dashed line $=95 \%$; solid line with diamonds $=99 \%$. Centers of the peaks are labeled in years. The null hypothesis was determined using the robust noise background estimation procedure (Mann and Lees 1996).

were extracted for 12.2 (eigenvector pair 3 and 4), 18.0 (pair 7 and 8), 21.7 (pair 1 and 2), and 50 (pair 5 and 6) yr. These periodicities accounted for $7.19 \%, 4.69 \%$, $10.72 \%$, and $4.64 \%$ of the streamflow variation, respectively.

In KRS, the above-noted reduction in variability from about 1850 to 1900 appears to coincide with an out of phase relationship between the 18.0- and 21.7-yr waveforms extracted from SSA (Figs. 6a,c). Conversely, greater variability is seen when these two modes are in phase (Figs. 6a,c). The 21-yr waveform for UNP shows similar fluctuations in time and amplitude (Fig. 6b). MEM analysis of the UNP 21-yr waveform shows that it is composed of 18.2- and 21.3-yr periodicities (Fig. 7). In both reconstructions, changes in variability and extreme 5-yr episodes (Figs. 4a,b) appear to coincide temporally with changes in the phase relationship of the 18- and 22-yr waveforms (Fig. 6c).

The existence of bidecadal periodicity in these reconstructions suggests the possibility of solar influence (Mitchell et al. 1979; Stockton et al. 1983; Hoyt and Schatten 1997; Cook et al. 1997). The BT cross-spectral analysis between KRS, the reconstruction with the strongest and most consistent bidecadal waveform, and the annual Wolf sunspot numbers (obtained from the National Geophysical Data Center and characterized by

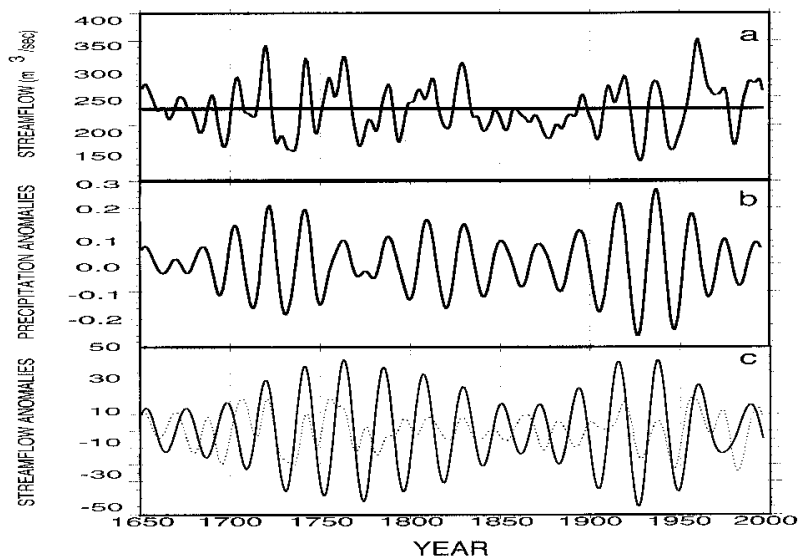

FIG. 6. (a) 10-yr running average of the Kherlen River streamflow reconstruction (KRS). The solid, flat line shows the reconstruction mean. (b) The 21-yr waveform of UNP extracted by SSA. (c) The 22- (thick line) and 18- (dashed line) yr waveforms extracted from KRS using SSA. The shaded areas show intervals of reduced streamflow (a) and precipitation amplitude (b) that correspond to intervals when the 22- and 18-yr waveforms are out of phase (c).

a significant, broad band of spectral power at 7.6-13.1 yr) for the common period 1700-1995 revealed significant (95\% level) coherency at 20-23 yr. The 11-yr sunspot cycle has magnetic polarity in alternating cycles forming the 22-yr Hale magnetic solar cycle (Hale 1924; Shove 1983) that has been hypothesized as having influence on drought cycles (Mitchell et al. 1979; Stockton et al. 1983; Cook et al. 1997).

\section{Discussion}

The reconstructions presented herein for northeastern Mongolia provide longer time series for evaluation of

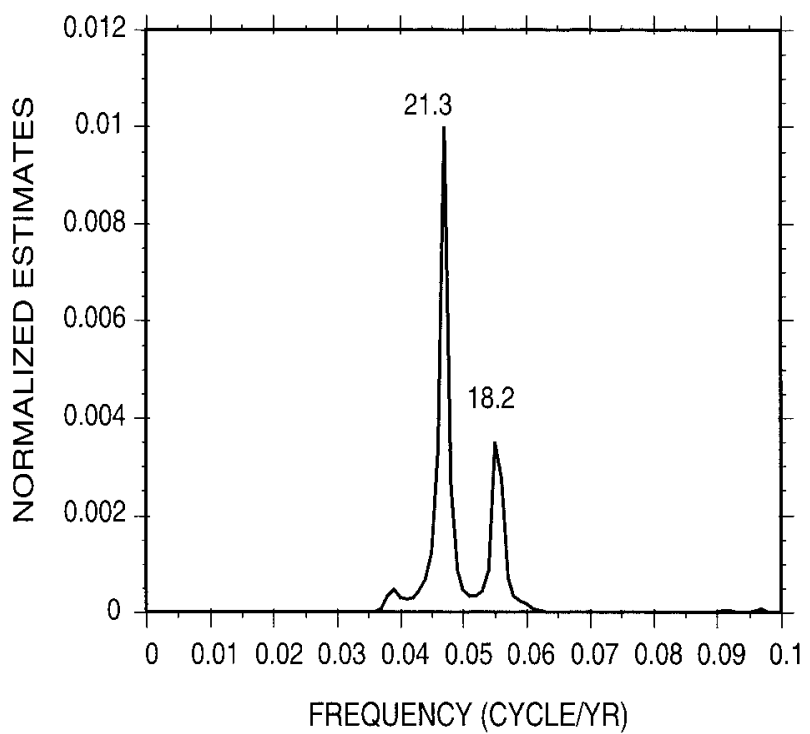

FIG. 7. MEM spectrum of the UNP 21-yr waveform. Centers of the peaks are labeled in years. 
precipitation and streamflow variability, extending the available instrumental record by nearly $300 \mathrm{yr}$. Our evaluations of both standard deviation and extreme dry and wet 5-yr intervals suggest that variations over the recent period of instrumental data are not unusual relative to the prior record. Previous analysis of recorded precipitation data for Mongolia indicated an increase in summer precipitation over the past half-century (Dagvadorj and Mijiddorg 1996). Inspection of the UNP and KRS reconstructions shows several periods of decadal oscillations (Figs. 4a,b), suggesting that the trend from 1942 to 1995 was not exceptional. It must be noted that the reconstructions are annual proxies and may not show changes in winter or spring precipitation. It should also be noted that extended wet periods appear to occur more frequently in the twentieth century (Figs. 4a,b). Thus, although the climate of the twentieth century does seem to have slightly more variable streamflow and indications of extended wet periods, it is difficult to state clearly that recent periods are unusual versus the previous three centuries. We therefore conclude that, as of 1995, annual precipitation and streamflow over the previous 50 years appear to have been within the range of natural variation since 1651 .

We compared our reconstructions with a record of drought for eastern Mongolia, derived from historical documents, extending from 1740 to 1939 (Mijiddorj and Namhay 1993). There is good agreement with our reconstructions and the historical reconstruction. The best agreements are found after 1880 and with the 1925 drought, which covered an estimated $70 \%$ of eastern Mongolia. Between 1880 and 1939 we can only speculate that the historical record may have improved because of increased observations, better spatial coverage, or better document preservation. Our reconstructions also give perspective for the historical drought reconstruction for eastern Mongolia (Mijiddorj and Namhay 1993). The tree-ring records show that the 1925 drought was one of the most severe in the last 350 years. Many droughts estimated to cover $50 \%$ of eastern Mongolia occurred in the 1800s (Mijiddorj and Namhay 1993). Our reconstructions capture these droughts but show more severe droughts in the 1720s and 1730s (Table 2, Figs. 4a,b). Also, Mijiddorj and Namhay (1993) stated that a drought in 1827 covered an estimated $70 \%$ of their study area. This was neither supported by the reconstructions nor by the raw tree-ring measurements. Interestingly, 1828 has one of the most consistent false rings in the Urgun Nars trees, occurring in $32 \%$ of the samples. Previous work has shown false latewood formation in drought sensitive trees to be a result of a seasonal drought followed by normal or wet conditions (Douglass 1919; Villalba and Veblen 1996). The historical drought reconstruction does not have seasonal resolution, so we can only speculate that a seasonal drought before or early in 1828 caused the formation of the false ring.

The period of pronounced low variability from about
1850 to 1900 (Figs. 4a,b), and the indication that this interval coincides with an out of phase relationship between the 18- and 22-yr waveforms (Figs. 6a,b,c) is a noteworthy feature of both reconstructions (Figs. 4a,b). Interestingly, these waveforms are strikingly similar to bidecadal waveforms identified in tree-ring reconstructions of drought area indexes for the western United States (Cook et al. 1997). Further, the waveforms identified by Cook et al. (1997) also show a reduction in amplitude during the mid- to late 1800 s to early 1900 s. In both the Mongolian and western USA reconstructions, these bidecadal waveforms account for at least $10 \%$ of the overall variance.

The bidecadal mode of variation is most significant in the KRS streamflow series. It has been suggested that the streamflow parameter may be one of the most sensitive for detection of the influence of the solar cycle on climate, based on the principle that streamflow integrates hydrometeorological effects over a large region, and amplifies small fluctuations in rainfall (Hoyt and Schatten 1997). It has been suggested that the existence of a bidecadal mode of variation in the drought-sensitive reconstructions for the western United States is consistent with possible solar influence (Cook et al. 1997), confirming earlier studies (Mitchell et al. 1979; Stockton et al. 1983). The existence of a similar mode of variation, particularly in the KRS series comprised of two chronologies covering a large geographic area, appears to suggest a similar influence in Mongolia. Quasi-solar periodicities have also been noted in Mongolian meteorological data (Mijiddorj and Namhay 1993) and tree-ring records (Lovelius et al. 1992), as well as in a drought reconstruction from the Hengduan Mountains, China (Wu et al. 1988). The broadband power spectra in the 10-13- and 20-24-yr periodicities indicate other potential forcings of precipitation in Mongolia. Recent paleoclimatic studies suggest the Asian monsoon has changed in intensity throughout the Holocene (An and Thompson 1998; Feng et al. 1999). Indeed, changes in major circulation systems may have decadal- or multidecadal-scale influence. Therefore, the development of a network of sites across Mongolia and further tests are needed to refute or support the hypothesis of some solar forcing on precipitation.

There are a few theoretical mechanisms for the influence of solar activity on precipitation. One is that at the sunspot maximum more energy is put into the earth's atmosphere. This causes the Hadley cell to expand intensifying the intratropical conversion zone and increasing precipitation while lowering mean surface pressure (Hoyt and Schatten 1997). Modeling efforts using GCMs similarly suggest that variations in solar energy input would alter tropospheric stability and processes including low-pressure systems in the extratropics (National Resource Council 1994). This hypothesized mechanism has been developed further in a recent climate modeling experiment (Shindell et al. 1999). Solar cycle variability was observed in the model to have an 
effect on the stratospheric ozone layer. Changes in stratospheric ozone and winds affect the flow of energy at altitudes just below these changes, which then affect the next lower levels. This downward control in the atmosphere can cause changes in planetary waves and influence lower-atmospheric temperature and pressure. These findings also imply that the observed $10-12-\mathrm{yr}$ oscillations in geopotential height near the earth's surface may be partially driven by solar variability (Shindell et al. 1999). Finally, new research suggests that solar wind may cause the formation of clouds at high latitudes (Feynman and Ruzmaikin 1999). The effect on precipitation may be small, making the solar fingerprint hard to detect. Since streamflow data may contain less noise relative to other hydrometeorological variables, its use might improve detection of possible solar effects (Hoyt and Schatten 1997).

\section{Summary}

High quality tree-ring chronologies were used to reconstruct annual precipitation and streamflow for the data-sparse region of northeastern Mongolia from 1651 to 1995 . The tree-ring streamflow model accounted for more variance than the instrumental precipitation data. The hydrometeorological variations observed for the recent period of instrumental data are within the range reconstructed for the past 345 years. The reconstructions herein appear to show more frequent extended wet periods in recent decades. However, this study does not demonstrate unequivocal evidence of an increase in precipitation as suggested by some climate models (e.g., Kattenburg et al. 1996). An overall appraisal of trends in Mongolian precipitation must await a more geographically comprehensive analysis.

The identification of significant periodicities at around 12 and $20-24$ yr suggests that there is possible evidence for solar influences in these reconstructions for northeastern Mongolia. A period of pronounced low variability around $1850-1900$ in both series appears to coincide with an out of phase relationship between two bidecadal modes of variation, a pattern that also appears evident in drought reconstructions in the western United States. These findings lend support to the hypothesis of possible solar influence as reflected in tree-ring time series, first proposed by Douglass (1919). Although we do not have a mechanism for such influence at this time, this convergence of spectral results in these distant continental climates may inspire more attention to the development of hypotheses (Hoyt and Schatten 1997). Development of additional chronologies from drought-sensitive sites will likely improve the quality of such reconstructions in future efforts while providing more data and coverage with which to test hypotheses on possible influence of solar effects and other forcings on the climate of Mongolia.

Acknowledgments. We thank H. Grissino-Mayer for his assistance in obtaining obscure references, D. Pederson and H. Cullen for technical assistance. We thank R. Villalba, J. Kush, D. Frank, and three anonymous reviewers for constructive comments. This research was aided by the cooperation of the Hydrometeorological Research Institute, Institute of Biological Sciences, and the Ministry for Nature and the Environment in Mongolia. The research was supported by the United States National Science Foundation, Paleoclimate Program Grant ATM 96-31750.

\section{REFERENCES}

An, Z. S., and L. G. Thompson, 1998: Paleoclimatic change of monsoonal China linked to global change. Asian Change in the Context of Global Climate Change, J. Galloway and J. Melillo, Eds., Cambridge University Press, $18-41$.

Blasing, T. J., D. N. Duvick, and D. C. West, 1981: Calibration and verification using regionally averaged single station precipitation data. Tree-Ring Bull., 41, 37-44.

Boninsegna, J. A., 1992: South American dendroclimatological records. Climate Since A.D. 1500, R. S. Bradley and P. D. Jones, Eds., Routledge, 446-462.

Briffa, K. R., 1995: Interpreting high-resolution proxy climate dataThe example of dendroclimatology. Analysis of Climate Data Variability, Applications of Statistical Techniques, H. von Storch and A. Navarra, Eds., Springer, 77-94.

Cleaveland, M. K., and D. W. Stahle, 1989: Tree Ring Analysis of surplus and deficit runoff in the White River, Arkansas. Water Resour. Res., 25, 1391-1401.

Cook, E. R., 1985: A time series analysis approach to tree-ring standardization. Ph.D. thesis, University of Arizona, 171 pp. [Available from The University of Arizona, Tucson, AZ 85721.]

, and G. C. Jacoby, 1983: Potomac River streamflow since 1730 as reconstructed by tree rings. J. Climate Appl. Meteor., 22, $1659-1672$.

—, and L. A. Kairiukstis, Eds., 1990: Methods of Dendrochronology. Kluwer Academic, 394 pp.

, K. R. Briffa, and P. D. Jones, 1994: Spatial regression methods in dendroclimatology: A review and comparison of two techniques. Int. J. Climatol., 14, 379-402.

, D. M. Meko, and C. W. Stockton, 1997: A new assessment of possible solar and lunar forcing of the bidecadal drought rhythm in the western United States. J. Climate, 10, 1343-1356.

Dagvadorj, D., and R. Mijiddorj, 1996: Climate change issues in Mongolia. Hydrometeorological Issues in Mongolia: Papers in Hydrometeorology, D. Dagvadorj and L. Natsagdorj, Eds., Hydrometeorological Research Institute, 79-88.

Dai, A., and K. E. Trenberth, 1998: Global variations in droughts and wet spells: 1900-1995. Geophys. Res. Lett., 25, 3367-3370.

D'Arrigo, R. D., and G. C. Jacoby, 1991: A 1000-year record of winter precipitation from northwestern New Mexico, USA: A reconstruction from tree-rings and its relation to El Niño and the Southern Oscillation. Holocene, 1, 95-101.

Douglass, A. E., 1919: Climatic Cycles and Tree-Growth: A Study of the Annual Rings of Trees in Relation to Climate and Solar Activity. Carnegie Institution of Washington, $127 \mathrm{pp}$.

Draper, N. R., and H. Smith, 1981: Applied Regression Analysis. John Wiley \& Sons, 709 pp.

Feng, X., H. Cui, K. Tang, and L. E. Conkey, 1999: Tree-ring $\delta \mathrm{D}$ as an indicator of Asian Monsoon intensity. Quat. Res., 51, 262266.

Feynman, J., and A. Ruzmaikin, 1999: Modulation of cosmic ray precipitation related to climate. Geophys. Res. Lett., 26, 20572060.

Fritts, H. C., 1976: Tree Rings and Climate. Academic Press, 567 pp.

Grissino-Mayer, H. D., 1996: A 2129-year reconstruction of precip- 
itation for northwestern New Mexico, USA. Tree Rings, Environment and Humanity, J. S. Dean, D. M. Meko, and T. W. Swetnam, Eds., The University of Arizona, 191-204.

Hale, G. E., 1924: The law of sun-spot polarity. Nat. Acad. Sci. (USA) Proc., 10, 53-55.

Holmes, R. L., 1983: Computer-assisted quality control in tree-ring data and measurement. Tree-Ring Bull., 43, 69-78.

Hoyt, D. V., and K. H. Schatten, 1997: Rainfall. The Role of the Sun in Climate Change, D. V. Hoyt and K. H. Schatten, Eds., Oxford University Press, $125-142$.

Hughes, M. K., X. Wu, X. Shoa, and G. M. Garfin, 1994: A preliminary reconstruction of rainfall in north-central China since A.D. 1600 from tree-ring density and width. Quat. Res., 42, 88-99.

Jacoby, G. J., R. D. D’Arrigo, and Ts. Davaajamts, 1996: Mongolian tree rings and 20th-century warming. Science, 273, 771-773.

Jenkins, G. M., and D. G. Watts, 1968: Spectral Analysis and its Application. Holden-Day, 525 pp.

Kattenberg, A., F. Giorgi, H. Grassl, G. A. Meehl, J. F. B. Mitchell, R. J. Stouffer, T. Tokioka, A. J. Weaver, and T. M. L. Wigley, 1996: Climate models-Projections of future climate. Climate Change 1995: The Science of Climate Change, Cambridge University Press, $572 \mathrm{pp}$.

Kramer, P. J., and T. T. Kozlowski, 1979: Physiology of Woody Plants. Academic Press, 657 pp.

Linsley, R. K., M. A. Kohler, and J. L. H. Paulhus, 1949: Applied Hydrology. McGraw-Hill, 689 pp.

Lovelius, N. V., Ts. Davaajamts, and P. D. Gunin, 1992: Dendroindications of forest growth conditions in Mongolia and possibilities of forecasting (in Russian). Ecology and Use in Nature of Mongolia, S. N. Trudov, Ed., Russian Academy of Sciences, 3249.

Mann, M. E., and J. M. Lees, 1996: Robust estimation of background noise and signal detection in climatic time series. Climatic Change, 33, 409-445.

Marple, S. L., Jr., 1987: Digital Spectral Analysis with Applications. Prentice-Hall, 289 pp.

Meiyu, Y., L. Yimin, and D. Min, 1995: The influence of sea surface temperature anomaly on seasonal precipitation and temperature in northwest China and central Asia. Climatic Change in Arid and Semi-Arid Region of the Central Asia, Mongolia Hydrometeorological Service, 13-20.

Mijiddorj, R., and A. Namhay, 1993: On drought and unfavorable winter conditions recurrence in Mongolia (in Russian). Trans. HMRI, 11, 118-131.

Mitchell, J. M., Jr., C. W. Stockton, and D. M. Meko, 1979: Evidence of a 22-year rhythm of drought in the western United States related to the Hale solar cycle since the 17 th century. SolarTerrestrial Influences on Weather and Climate, B. M. McCormac and T. A. Seliga, Eds., D. Reidel, 125-144.

National Resource Council, 1994: Solar variations and climate change. Solar Influences on Global Change, E. A. Frieman, Ed., National Academy Press, 23-47.

Percival, D. B., and A. T. Walden, 1993: Multitaper spectral estimation. Spectral Analysis for Physical Applications: Multitaper and Conventional Univariate Techniques, D. B. Percival and A. T. Walden, Eds., Cambridge University Press, 331-377.

Price, M. P., and N. D. Simpson, 1913: An account of the plants collected by Mr. M. P. Price on the Carruthers-Miller-Price ex- pedition throughout northwest Mongolia and Chinese Dsungaria in 1910. J. Linn. Soc. London Bot., 41, 385-456.

Samel, A. N., W. C. Wang, and X. Z. Liang, 1999: The monsoon rainband over China and relationships with the Eurasian circulation. J. Climate, 12, 115-131.

Schulman, E., 1945: Tree-rings and runoff in the South Platte River basin. Tree-Ring Bull., 11, 18-24.

Shindell, D., D. Rind, N. Balachandran, J. Lean, and P. Lonergan, 1999: Solar cycle variability, ozone, and climate. Science, 284, 305-308.

Shove, D. J., 1983: Editor's comments on papers 24 through 28. Sunspot Cycles, D. J. Shove, Ed., Hutchinson Ross Publishing Company, 192-198.

Stahle, D. W., and M. K. Cleaveland, 1992: Reconstruction and analysis of spring rainfall over the southeastern U.S. for the past 1000 years. Bull. Amer. Meteor. Soc., 73, 1947-1961.

Stockton, C. W., and G. C. Jacoby, 1976: Long-term surface-water supply and streamflow trends in the Upper Colorado River basin based on tree-ring analyses. Lake Powell Res. Proj. Bull., 18, $70 \mathrm{pp}$.

_ J. M. Mitchell, and D. M. Meko, 1983: A reappraisal of the 22 -year drought cycle. Solar-Terrestrial Influences on Weather and Climate, B. M. McCormac, Ed., Colorado Associated University Press, 507-515.

Stokes, M. A., and T. L. Smiley, 1968: An Introduction to Tree-Ring Dating. University of Chicago Press, $73 \mathrm{pp}$.

Vautard, R., 1995: Patterns in time: SSA and MSSA. Analysis of Climate Variability, Applications of Statistical Techniques, H. von Storch and A. Navarra, Eds., Springer, 259-279.

Villalba, R., and T. T. Veblen, 1996: A tree-ring record of dry springwet summer events in the forest-steppe ecotone, northern Patagonia, Argentina. Tree Rings, Environment and Humanity, J. S. Dean, D. M. Meko, and T. W. Swetnam, Eds., University of Arizona, 107-116.

Wang, C. W., 1961: The Forests of China. Cabot Foundation Publication No. 5, Harvard University Press, 313 pp.

Wigley, T. M. L., K. R. Briffa, and P. D. Jones, 1984: On the average value of correlated time series, with applications in dendroclimatology and hydrometeorology. J. Climate Appl. Meteor., 23, 201-213.

Wu, X. D., 1992: Studies in China. Climate Since A.D. 1500, R. S. Bradley and P. D. Jones, Eds., Chapman and Hall, Inc., 437443.

- L. Zhenyao, and S. Li, 1988: A preliminary study on the climatic change of the Hengduan Mountains area since 1600 A.D. Adv. Atmos. Sci., 5, 437-443.

Xue, Y., 1996: The impact of desertification in the Mongolian and the inner Mongolian grassland on the regional climate. J. Climate, 9, 2173-2189.

Yatagai, A., and T. Yasunari, 1994: Trends and decadal-scale fluctuations of surface air temperature and precipitation over China and Mongolia during the recent 40 year period (1951-1990). J. Meteor. Soc. Japan, 72, 937-957.

— in the arid/semi-arid regions in China and Mongolia: Their regionality and relation to the Asian Summer Monsoon. J. Meteor. Soc. Japan, 73, 909-923.

Young, K. C., 1994: Reconstructing streamflow time series in central Arizona using monthly precipitation and tree ring records. $J$. Climate, 7, 361-374.

Zhang, J., and Z. Lin, 1992: Climate of China. Wiley, 376 pp. 